\title{
Identification and characterisation of mosquitoes from different locations of Qatar in 2017-2019
}

\author{
Elmoubasher Abu Baker Abd Farag,a,* (D), Devendra Bansal ${ }^{1, a}$ (D), Khaled Mardini ${ }^{2}$ (D), Ali A. Sultan ${ }^{3}$ (D), \\ Mohammed Hamad J. Al-Thani ${ }^{1}$, Salih Ali Al-Marri ${ }^{1}$, Mohammed Al-Hajri ${ }^{1}$, Hamad Al-Romaihi ${ }^{1}$, \\ and Francis Schaffner ${ }^{4,5, * a}$ (D) \\ ${ }^{1}$ Ministry of Public Health, Doha, Qatar \\ ${ }^{2}$ Friends of the Environment Center, Doha, Qatar \\ ${ }^{3}$ Department of Microbiology and Immunology, Weill Cornell Medicine, Cornell University, Doha, Qatar \\ ${ }^{4}$ Francis Schaffner Consultancy, 4125 Riehen, Switzerland \\ ${ }^{5}$ National Centre for Vector Entomology, Institute of Parasitology, Vetsuisse and Medical Faculty, University of Zurich, \\ 8057 Zurich, Switzerland
}

Received 15 July 2021, Accepted 25 November 2021, Published online 16 December 2021

\begin{abstract}
Mosquito-borne infections have considerable consequences for public health. The mere presence of a single case of vector-borne disease (VBD) introduces a risk to the local community particularly when associated with the compatible vector, host, and suitable environmental factors. Presently, there is no well-established vector control and surveillance programme in Qatar; therefore, the likelihood of VBDs spreading is undetermined. As a result, there is a pressing need to address this gap and enable successful management of VBDs. This study presents the results of three consecutive field surveys conducted between 2017 and 2019 with the aim of defining the types and distribution of mosquitoes that are of public health importance in Qatar. The results of the adult mosquito trappings show that the southern house mosquito Culex quinquefasciatus is the most widespread and abundant mosquito species, followed by $C x$. perexiguus, both species representing a risk of West Nile virus transmission. All sampling methods show that the malaria vector Anopheles stephensi is widespread including in urbanised areas, suggesting a risk of local malaria transmission. The wetland mosquito Aedes caspius is also widespread, representing a risk of Rift Valley fever virus transmission. The dengue vector Ae. aegypti was not detected and can be considered neither widespread nor abundant, suggesting a minimal risk for local transmission of dengue, chikungunya and Zika viruses. Interestingly, the study detected Culiseta longiareolata for the first time in Qatar. Regular field studies are needed to further address the knowledge gaps in terms of distribution, ecology, and biting habits of different mosquito species currently present in Qatar to accurately assess the risk of mosquito-borne diseases.
\end{abstract}

Key words: Culicidae, Distribution, Vector species, Surveillance, Qatar, Arabic Peninsula.

Résumé - Identification et caractérisation des moustiques de différents sites du Qatar en 2017-2019. Les maladies transmises par les moustiques posent de considérables risques en santé publique. La simple présence d'un cas de maladie à transmission vectorielle (MTV) introduit un risque pour la communauté locale lorsque associé à un vecteur, un hôte et des facteurs environnementaux compatibles. À ce jour il n'y a pas de programme de surveillance et de contrôle des vecteurs bien établi au Qatar, et de ce fait la probabilité de diffusion de MTV est indéterminée. C'est pourquoi il existe un besoin pressant de combler ce vide et de permettre une gestion effective des MTV. Ce travail présente les résultats de trois études de terrain successives conduites entre 2017 et 2019, dans l'objectif de caractériser les moustiques d'importance en santé publique et leur distribution au Qatar. Les résultats des piégeages d'adultes révèlent que le moustique domestique méridional Culex quinquefasciatus est l'espèce la plus répandue et abondante, suivie de $C x$. perexiguus, les deux espèces présentant un risque pour la transmission du virus West Nile. L'ensemble des échantillonnages montrent que le vecteur du paludisme Anopheles stephensi est largement répandu y compris dans les zones urbanisées, ce qui suggère un risque de transmission locale du paludisme. Le moustique des zones humides Aedes caspius est également largement répandu, présentant un risque pour la transmission du virus de la fièvre de la Vallée du Rift. Le vecteur de la dengue Ae. aegypti n'a pas été détecté et peut être considéré ni répandu ni abondant, ce qui suggère un risque minimal de transmission locale des

*Corresponding authors: eabdfarag@moph.gov.qa; fschaffner.consult@gmail.com

${ }^{\text {a }}$ These authors contributed equally to this work.

This is an Open Access article distributed under the terms of the Creative Commons Attribution License (https://creativecommons.org/licenses/by/4.0), which permits unrestricted use, distribution, and reproduction in any medium, provided the original work is properly cited. 


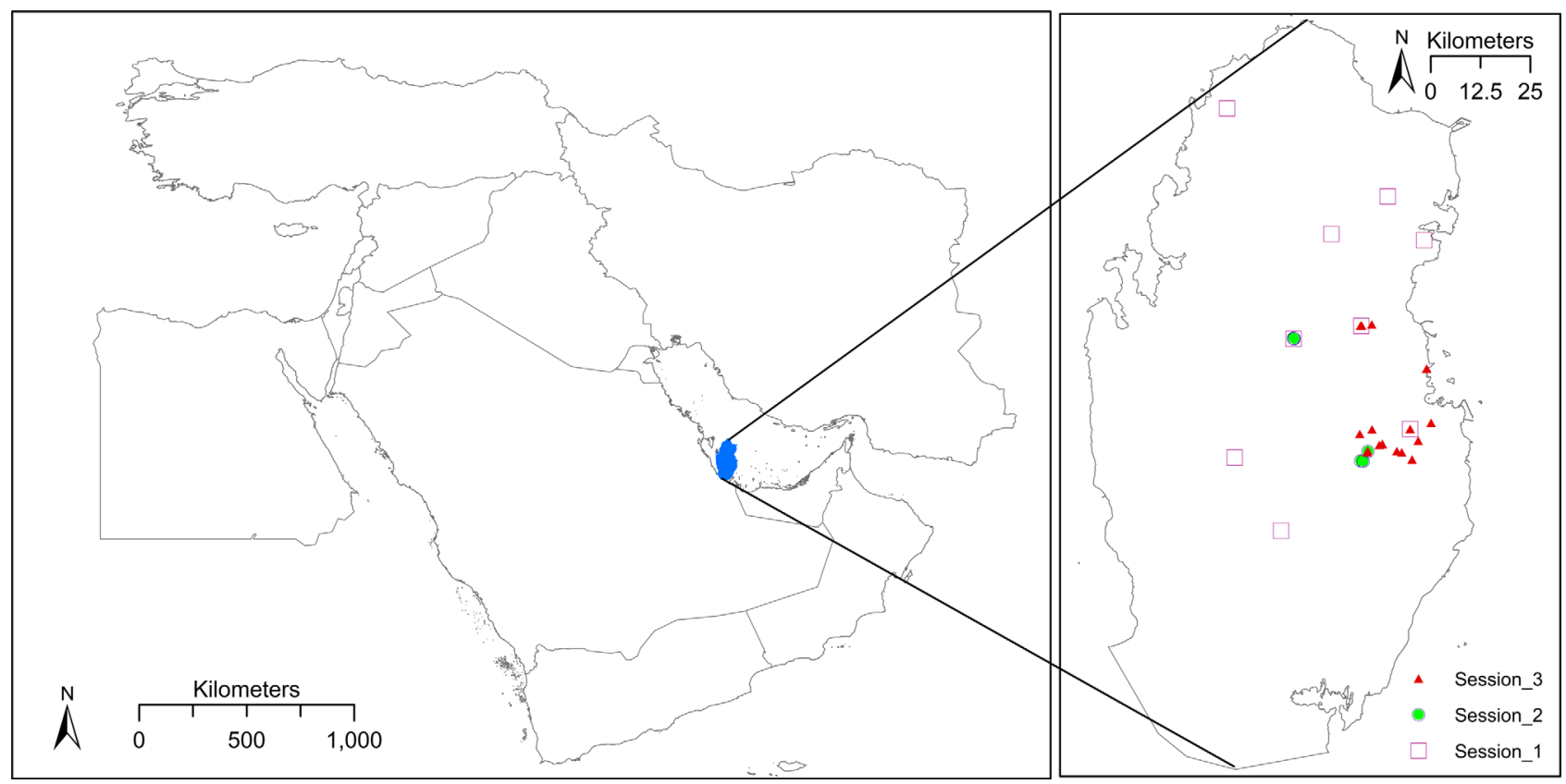

Figure 1. Study area and site locations. A. Location of the study area: Qatar, Middle East; B. Location of the study sites. White squares: Session 1 - longitudinal data, 2017-2018; Green circles: Session 2 - field survey, September 2017; Red triangles: Session 3 - cross-sectional field study, January 2019.

$5.7 \%$ (670 sq. $\mathrm{km}$ in 2016) of agricultural land [5]. The country is divided into eight municipalities. Qatar's climate is classified as a hot desert (Köppen-Geiger category BWh), with an annual mean temperature of $27.1^{\circ} \mathrm{C}$ and mean rainfall of $72 \mathrm{~mm}$ (most rainfall is between October and May) [6].

\section{Field sampling}

\section{Session 1: Longitudinal sampling, 2017-2018}

A series of repeated sampling (longitudinal) sessions were carried out to collect adult mosquito samples from across the country over a period of one year, to account for seasonal data. A total of nine locations were selected across the country to account for different environment sub-types that would influence mosquito breeding such as farms, gardening centres, and zoos (Table 1, Fig. 1).

Adult mosquitoes were collected through MozzTech Mosquito Traps (Ridpest, Malaysia) baited with Octenol and $\mathrm{CO}_{2}$ that is produced by photocatalytic reaction of titanium dioxide exposed to black light. The traps were set for two consecutive nights each week between August 2017 and August 2018. The mosquitoes caught by this process were collected daily in the morning, and then frozen once transported to the laboratory for sorting and identification under a stereo microscope.

\section{Session 2: Field survey, September 2017}

To obtain an overview and insight about the mosquito breeding habits in Qatar, five sites previously known to local municipality's pest control workers as common sites for mosquito breeding were inspected for three days (September 18-20, 2017) (Table 1, Fig. 1). Two strategies were used to collect larval samples: (i) using a net with a fine mesh and then transferring the samples to a 1-L white plastic tray for observation; and (ii) filling the tray by directly dipping it in water. Larvae and pupae collected using these techniques were transferred with water to a vial for transport to the laboratory. There, 4th instar larvae were transferred to a $70 \%$ ethanol solution and young larvae and pupae were kept until they grew to 4th instar or emergence of adults. In addition, resting catches were performed by using sweep nets around vegetation, and human landing catches were performed by netting around a person. In both cases, adults were collected from the net via a mouth aspirator and brought to the laboratory.

\section{Session 3: Cross-sectional field study, January 2019}

A cross-sectional study was conducted with the aim of updating the pre-existing database of the mosquito fauna of Qatar, for species presence at as many sites as possible. A total of 18 sites were selected across the country for collecting the mosquito samples. These sites were selected to ensure rapid collection and transport of the samples to the laboratory within a one-day trip. These sites covered all possible ranges of environments, e.g. urban building areas, farms, garden centres, industrial areas, sewage lakes, wetlands, worker houses, and zoos (Table 1, Figs. 1 and 2). All the samples were collected between January 15-23, 2019. The choices of sites were guided by municipalities' pest control workers, satellite images and/or visually along roads in the course of journeys. Larval samplings, resting catches and human landing catches were performed at 
Table 1. Location and characteristics of sampling sites [F1-F9: Longitudinal survey, session 1; Q01-Q20 Field surveys, session 2 (September 2017) and 3 (January 2019)], with sampling method, period, and number of samples analysed.

\begin{tabular}{|c|c|c|c|c|c|c|c|c|}
\hline Site ID & Municipality & Location & Habitat & Latitude & Longitude & Method & Period & No. samples \\
\hline F1 & Al Doha & Widam Company & Garden centre & 25.235981 & 51.485530 & Adult trapping & Aug-17 to & 12 \\
\hline $\mathrm{F} 2$ & Al Khor & Al Sidra Farm & Farm & 25.675798 & 51.307606 & Adult trapping & Aug-18 & 12 \\
\hline F3 & Al Khor & Sewage Treatment Plant & Sewage basins & 25.661767 & 51.517150 & Adult trapping & & 9 \\
\hline $\mathrm{F} 4$ & Al Khor & Umm Barkah & Farm & 25.760504 & 51.434899 & Adult trapping & & 13 \\
\hline F5 & Al Rayyan & Al Rekkiya & Farm & 25.006483 & 51.194028 & Adult trapping & & 10 \\
\hline F6 & Al Shahaniya & $\mathrm{Al}$ Dosari park and game & Zoo & 25.439317 & 51.222233 & Adult trapping & & 15 \\
\hline F7 & Al Shahaniya & Umm Weshah & Farm & 25.171333 & 51.089283 & Adult trapping & & 8 \\
\hline F8 & Al Shamal & Al Zobara & Farm & 25.959183 & 51.072083 & Adult trapping & & 9 \\
\hline F9 & Umm Salal & Al Siletin & Farm & 25.468589 & 51.375235 & Adult trapping & & 11 \\
\hline \multirow[t]{2}{*}{ Q01a } & Al Shahaniyah & Al Dosari park and game & $\begin{array}{l}\text { Basin beside fish pond, } \\
\text { temporary }\end{array}$ & 25.440457 & 51.222572 & Larval sampling & Sep 17 & 1 \\
\hline & & & & & & Larval sampling & Jan 19 & 1 \\
\hline Q01b & Al Shahaniyah & Al Dosari park and game & Covered cistern & 25.440364 & 51.223533 & Larval sampling & Jan 19 & 1 \\
\hline Q01c & Al Shahaniyah & Al Dosari park and game & Tyre (dry) & 25.441110 & 51.222361 & Larval sampling & Jan 19 & 1 \\
\hline Q02 & Al Rayyan & Abu Nakhlah, sewage lake & Pond border with vegetation & 25.164420 & 51.377165 & Larval sampling & Sep 17 & 1 \\
\hline \multirow[t]{3}{*}{ Q03 } & Al Rayyan & Abu Nakhlah, sewage lake & Marsh border & 25.164499 & 51.373740 & Resting catch & Sep 17 & 1 \\
\hline & & & & & & Human landing catch & Sep 17 & 1 \\
\hline & & & & & & Human landing catch & Jan 19 & 1 \\
\hline \multirow[t]{2}{*}{ Q04 } & Al Rayyan & Abu Nakhlah, sewage lake & $\begin{array}{l}\text { Isolated puddles outside } \\
\text { embankment }\end{array}$ & 25.163673 & 51.379603 & Larval sampling & Sep 17 & 1 \\
\hline & & & & & & Larval sampling & Jan 19 & 1 \\
\hline Q05 & Al Rayyan & Abu Nakhlah, new village & Two metallic cisterns & 25.185860 & 51.390198 & Larval sampling & Sep 17 & 1 \\
\hline Q06 & Al Doha & Nuaija & Container & 25.249994 & 51.532889 & Larval sampling & Jan 19 & 1 \\
\hline Q07 & Al Rayyan & Abu Hamour & Flooded land with vegetation & 25.209601 & 51.503795 & Larval sampling & Jan 19 & 1 \\
\hline Q08 & Al Doha & Al Waab & Park/garden & 25.236129 & 51.485550 & Adult trapping & Jan 19 & 3 \\
\hline Q09 & Al Rayyan & Abu Sidra & Flooded land with vegetation & 25.235270 & 51.399403 & Larval sampling & Jan 19 & 1 \\
\hline Q10 & Al Rayyan & Al Maqran & Wetland & 25.224855 & 51.371550 & Larval sampling & Jan 19 & 1 \\
\hline Q11 & Al Rayyan & Abu Nakhlah, new village & Four containers & 25.186946 & 51.389706 & Larval sampling & Jan 19 & 1 \\
\hline Q12 & Al Rayyan & Abu Nakhlah, new village & Flooded land with vegetation & 25.183686 & 51.387945 & Larval sampling & Jan 19 & 1 \\
\hline Q13 & Al Doha & West Bay & Two road drains & 25.372495 & 51.522716 & Larval sampling & Jan 19 & 1 \\
\hline Q14a & Umm Salal & Al Silatin Agricultural Complex & Park/garden & 25.469579 & 51.376009 & Adult trapping & Jan 19 & 3 \\
\hline Q14b & Umm Salal & Al Silatin Agricultural Complex & Artificial rock pool & 25.469011 & 51.373434 & Larval sampling & Jan 19 & 1 \\
\hline Q15 & Umm Salal & Umm Salal Ali & Five uncovered cisterns & 25.471937 & 51.398886 & Larval sampling & Jan 19 & 1 \\
\hline Q16 & Al Rayyan & Industrial area & Road puddles with vegetation & 25.199847 & 51.415835 & Larval sampling & Jan 19 & 1 \\
\hline Q17a & Al Rayyan & Industrial area & One iron barrel & 25.202058 & 51.422577 & Larval sampling & Jan 19 & 1 \\
\hline Q17b & Al Rayyan & Industrial area & Worker house in construction & 25.202093 & 51.422830 & Resting catch & Jan 19 & 1 \\
\hline Q17c & Al Rayyan & Industrial area & Worker house, outdoor & 25.202546 & 51.422650 & Adult trapping & Jan 19 & 1 \\
\hline Q18 & Al Rayyan & Industrial area, Labour camp & $\begin{array}{l}\text { One basin/fountain and four } \\
\text { road drains }\end{array}$ & 25.167192 & 51.489907 & Larval sampling & Jan 19 & 1 \\
\hline Q19 & Al Rayyan & Industrial area & Worker house, outdoor & 25.186026 & 51.455459 & Adult trapping & Jan 19 & 1 \\
\hline Q20 & Al Rayyan & Asian town & Wetland & 25.183368 & 51.466513 & Larval sampling & Jan 19 & 1 \\
\hline
\end{tabular}


(A)

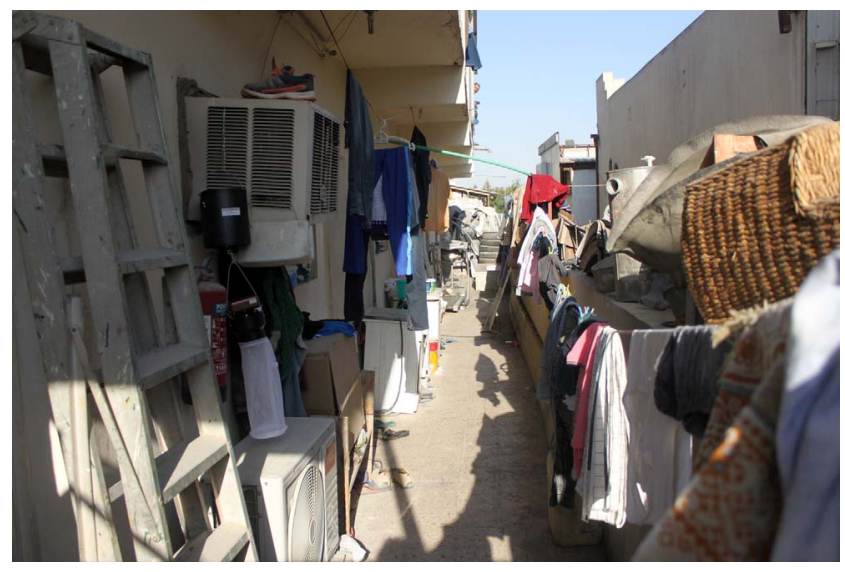

(C)

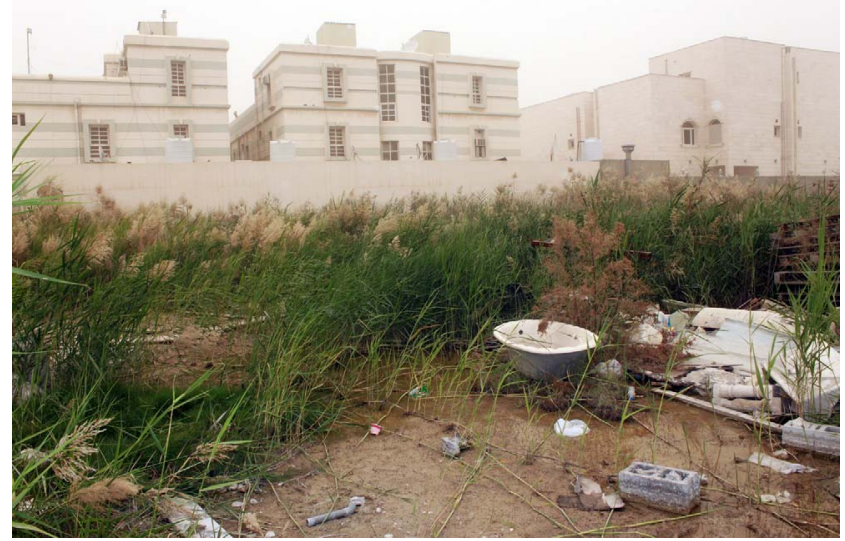

(E)

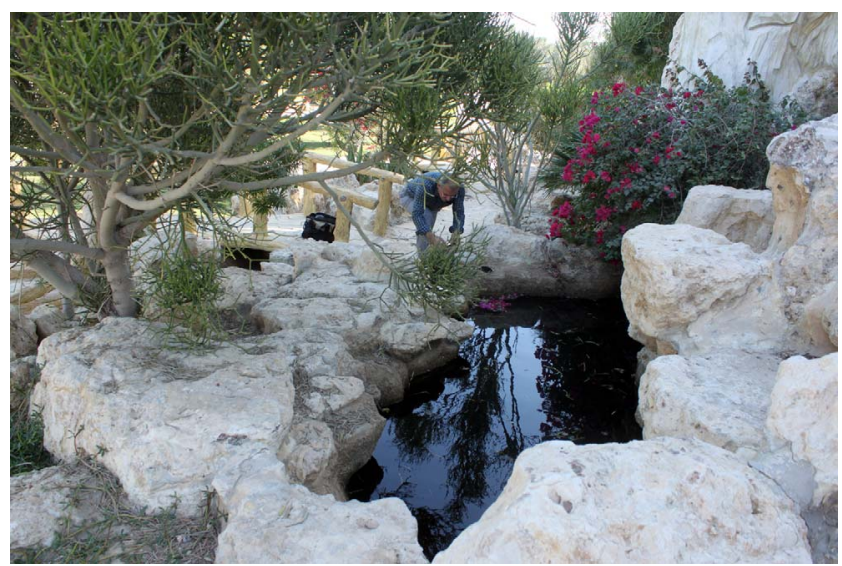

(B)

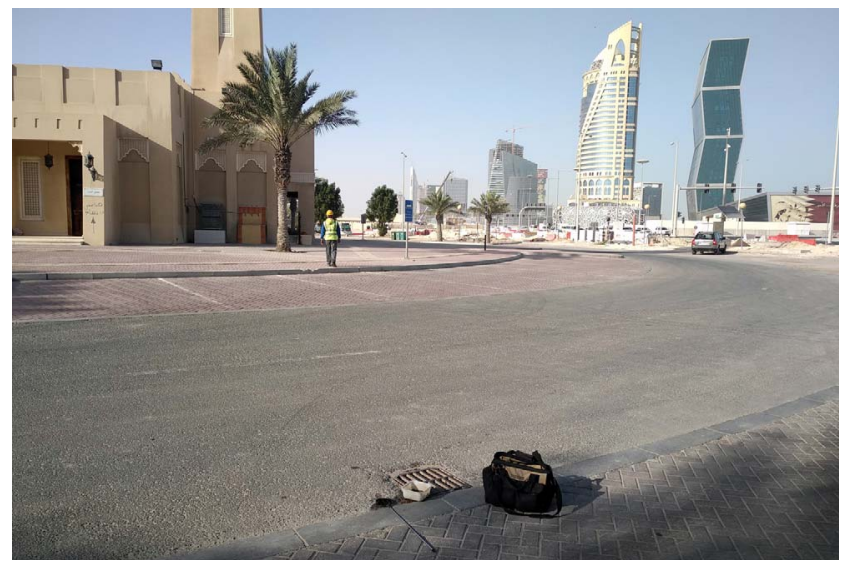

(D)

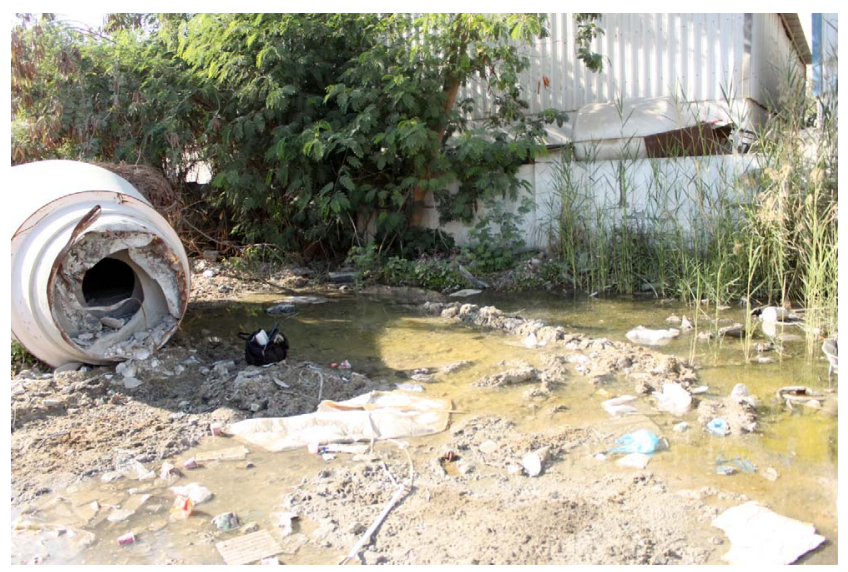

(F)

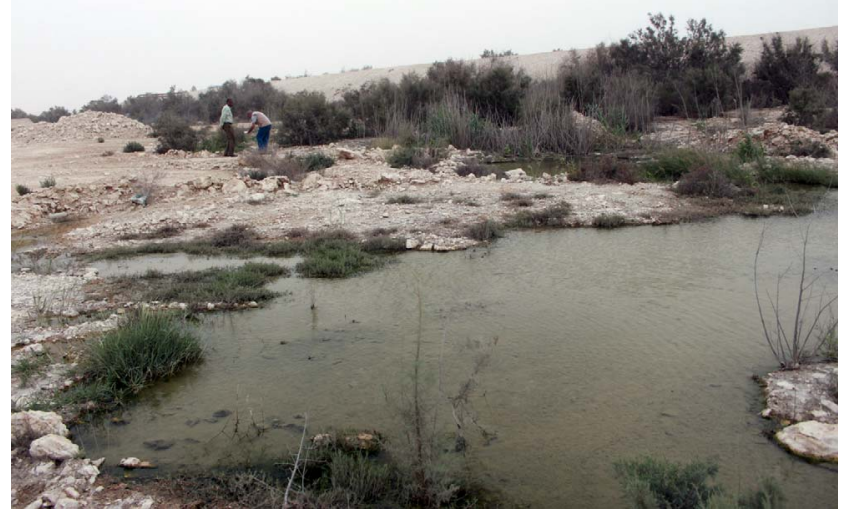

Figure 2. Examples of sites inspected for mosquitoes. A. Adult trapping at worker house, EVS trap (Q17c). Mosquito larval breeding sites: B. Road drain, breeding site for Culex quinquefasciatus (Q13); C. Flooded land in urban habitat, breeding site for Anopheles stephensi, Culex perexiguus, Culex quinquefasciatus, Culex tritaeniorhynchus (Q09); D. Flooded land in an industrial zone, breeding site for Anopheles stephensi, Culex perexiguus, Culex quinquefasciatus (Q16); E. Man-made container, positive for Anopheles stephensi, Culex quinquefasciatus, Culiseta longiareolata (Q14b); F. Wetland, breeding site for Aedes caspius, Anopheles stephensi, Culex perexiguus, Culex pusillus, Culex quinquefasciatus (Q04).

every selected site, as described for session 2 . In addition, adult trapping was performed with $\mathrm{CO}_{2}$-baited traps (Fig. 2A), i.e. Heavy Duty EVS trap (BioQuip Products Inc., USA), CDC Mini Light Trap (BioQuip Products Inc., USA) and BG-Sentinel
$2^{\mathrm{TM}}$ trap (Biogents, Germany). Traps were run overnight, and baited with dry ice at selected locations. Adults were collected with the trap net and brought to the laboratory, and frozen before identification. 
Table 2. Relative abundance of mosquito species collected in the longitudinal adult monitoring, per site, August 2017-September 2018, according to one sample per month per site. One black dot $=1-10$ individuals; Two black dots $=11-50$ individuals; Three black dots $=>50$ individuals.

\begin{tabular}{|c|c|c|c|c|c|c|}
\hline Site ID & $\begin{array}{l}\text { Aedes } \\
\text { caspius }\end{array}$ & $\begin{array}{l}\text { Anopheles } \\
\text { stephensi }\end{array}$ & $\begin{array}{c}\text { Cule } \\
\text { quinquefasciatus } \\
\text { group }\end{array}$ & $\begin{array}{c}\text { Culex } \\
\text { tritaeniorhynchus }\end{array}$ & $\begin{array}{c}\text { Culex } \\
\text { pusillus }\end{array}$ & $\begin{array}{c}\text { Culiseta } \\
\text { longiareolata }\end{array}$ \\
\hline $\mathrm{F} 1$ & - & 0 & & - & - & - \\
\hline $\mathrm{F} 2$ & 0 & 00 & & - & 0 & - \\
\hline F3 & - & - & & - & - & - \\
\hline $\mathrm{F} 4$ & O & 0 & & - & - & 0 \\
\hline F5 & - & - & 0 & - & - & - \\
\hline F6 & 0 & 0 & & - & 0 & 0 \\
\hline F7 & - & - & & - & - & - \\
\hline F8 & - & - & & - & - & - \\
\hline F9 & - & - & & 0 & - & 0 \\
\hline
\end{tabular}

\section{Mosquito identification}

\section{Morphology}

Mosquito larvae and adults (females and males) were classified as belonging to a species or, if not possible, to a group of morphologically closely related species based on standard identification keys using stereomicroscope [3, 7, 11, 12, 23]. Several subsamples of mosquito larvae and adults were preserved in ethanol (larvae and immature exuviae, male genitalia) or pinned in an insect box (adults). Molecular identification by DNA isolation and amplification of the mitochondrial cytochrome oxidase subunit I gene (COI) for Culex sp. or of the ribosomal internal transcribed spacer 2 (ITS2) for Anopheles sp. was performed on only a small fraction of total specimens, as described elsewhere [16, 26]. New sequences were deposited in GenBank with accession numbers OL653979, OL654412, OL672837, OL672843, and OL672844. In addition, a rapid polymerase chain reaction (PCR) assay that uses polymorphisms in the second intron of the acetylcholinesterase-2 (ACE2) locus was run for the identification of specimens of the $C x$. pipiens complex and possible hybrids [28].

\section{Results}

\section{Longitudinal data, 2017-2018}

Thousands of mosquitoes were collected in session 1 , but the presence of considerable by-catches (attracted by the black light) and the poor quality of preservation did not allow all specimens to be properly sorted and identified. However, to obtain an estimate of sampling outcomes under our time constraints, we performed subsampling and analysed one randomly chosen sample per month and per site.

We analysed 99 samples, yielding detection of seven mosquito species or groups, the most abundant being Culex quinquefasciatus species group (Cx. (Culex) pipiens (Linnaeus, 1758), Cx. (Cux.) quinquefasciatus Say, 1823, and Cx. (Cux.) perexiguus Theobald, 1903, which are almost impossible to distinguish as dried - and often damaged - adults) detected at all sites, followed by Anopheles (Cellia) stephensi Liston, 1901 collected at four sites (Table 2). No other Anopheles species was detected here. Culex quinquefasciatus gr. was highly abundant almost all over the year, whereas An. stephensi showed medium abundance in Oct-Nov and Jun-Jul (Table 3). A third species, Aedes (Ochlerotatus) caspius (Pallas, 1771), was detected at three sites only and at several periods over the year, but in small numbers. In addition, the species Culiseta (Allotheobaldia) longiareolata (Macquart, 1838) was found at three sites.

\section{Field studies, September 2017 and January 2019}

In sessions 2 and 3, a total of 20 sites were surveyed with 6 samples collected in 2017, and 27 in 2019 (Tables 1 and 4). This comprises 20 larval samplings, 2 adult human landing catches, 3 adult resting catches, and 8 adult trappings. Larval samplings yielded 933 larvae and 97 pupae, and entrapped adult mosquitoes accounted for 20 males and 101 females.

Seven mosquito species from four genera were observed: one Aedes, one Anopheles, four Culex, and one Culiseta (Table 5). All seven species were observed at both larval and adult (trapped or reared from immatures) stages, allowing accurate morphological identification. One specimen of An. stephensi (sample Q14b, adult female), two of Cx. perexiguus (samples Q04, adult male, and Q20, larvae) and one of $C x$. (Cux.) tritaeniorhynchus Giles, 1901 (sample Q10, adult male) were submitted to molecular identification and obtained COI or ITS2 sequences were compared with vouchers deposited in GenBank. Our An. stephensi sequence showed 100\% similarity with specimens from Iran and Iraq; $C x$. perexiguus sequences showed $100 \%$ identity with specimens from the United Arab Emirates, while the $C x$. tritaeniorhynchus sequence showed $>99 \%$ similarity with specimens from India, all confirming our morphological identification. Specimens of $C x$. quinquefasciatus were also submitted to molecular identification. A total of 45 specimens (adults and larvae, 1-6 specimens per sample, from all samples harbouring $C x$. quinquefasciatus except Q04 and Q19) were submitted to a PCR targeting the ACE2 locus and all obtained band traces on the gel showed characteristic Cx. quinquefasciatus bands (274 bp). Preliminary genomic analysis also suggested that there is no notable trace of hybridisation with $C x$. pipiens in the analysed genomes (Yuki Haba, pers. comm.). Culex quinquefasciatus was clearly the more abundant 
Table 3. Relative abundance and seasonality of mosquito species collected in the longitudinal adult monitoring, monthly, August 2017September 2018, according to one sample per month per site. One black dot $=1-10$ individuals; Two black dots $=11-50$ individuals; Three black dots $=>50$ individuals.

\begin{tabular}{|c|c|c|c|c|c|c|}
\hline $\begin{array}{l}\text { Month \& } \\
\text { Year }\end{array}$ & $\begin{array}{l}\text { Aedes } \\
\text { caspius }\end{array}$ & $\begin{array}{l}\text { Anopheles } \\
\text { stephensi }\end{array}$ & $\begin{array}{l}\text { Culex quinquefasciatus } \\
\text { group }\end{array}$ & $\begin{array}{c}\text { Culex } \\
\text { tritaeniorhynchus }\end{array}$ & $\begin{array}{c}\text { Culex } \\
\text { pusillus }\end{array}$ & $\begin{array}{c}\text { Culiseta } \\
\text { longiareolatc }\end{array}$ \\
\hline Aug-17 & - & - & - & - & - & - \\
\hline Sep-17 & - & - & ○ & - & 0 & - \\
\hline Oct-17 & - & ๑० & 00 & - & ○ & - \\
\hline Nov-17 & 0 & 0 & & 0 & - & - \\
\hline Dec-17 & - & 0 & 000 & - & - & - \\
\hline Jan-18 & 0 & - & 00 & - & - & - \\
\hline Feb-18 & - & - & & - & - & 0 \\
\hline Mar-18 & 0 & $\bullet$ & & - & - & - \\
\hline Apr-18 & ○ & $\bullet$ & & - & - & 0 \\
\hline May-18 & 0 & - & & - & - & - \\
\hline Jun-18 & - & 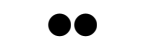 & & - & - & - \\
\hline Jul-18 & 0 & 00 & & - & ○ & - \\
\hline Aug-18 & - & - & & - & ○ & - \\
\hline
\end{tabular}

of the species, collected at 13 sites among 20 in total (Fig. 3), distributed in all land use categories (Fig. 4), and representing $48 \%$ of the collected individuals in total (Fig. 5). The lesser encountered species, Cs. longiareolata, was only found at two sites while all five remaining species were collected from five to eight different sites (Fig. 3). In terms of numbers of individuals, Cx. perexiguus and Cx. (Barraudius) pusillus Macquart, 1850 represented $20 \%$ and $18 \%$, respectively, while the four remaining species represented less than 5\%. Human landing catches revealed the occurrence of Ae. caspius only, while adult trappings also caught $C x$. quinquefasciatus $(88 \%$ of the caught individuals), Cx. tritaeniorhynchus (10\%) and An. stephensi (1\%), besides Ae. caspius (1\%) (Fig. 5). Comparing the species composition according to land use categories showed that all categories have significant mosquito diversity with at least four species among the seven found here. All species but Cs. longiareolata were found to occur in wetlands, and all but $C x$. pusillus in rural habitats. Similarly to $C x$. quinquefasciatus, $C x$. tritaeniorhynchus and An. stephensi were found in all land use categories (Fig. 4).

\section{Discussion}

Highly accurate and up-to-date data about the presence and distribution of various vector species are needed by public health authorities to assess the potential threat and devise effective counter strategies for VBDs. In the present study, three field survey sessions were conducted between 2017 and 2019 with the primary aim of collecting data on geographical, topographical, and seasonal distribution of various species of mosquitoes, in different regions of Qatar.

\section{Field data outcomes}

The samples from our entomological survey were collected from various sites to account for different factors that may influence the breeding capabilities and distribution of mosquitoes, including farms, garden centres, industrial areas, sewage lakes and sewage treatment plants, urban building areas, wetlands, worker houses, and zoos. In our survey, one or more species of mosquitoes were found at every inspected location, with the southern house mosquito species Cx. quinquefasciatus showing the widest geographical distribution. This is not surprising as this species is well adapted to breed in a wide range of habitats, from artificial collection of water in man-made containers to natural water bodies $[7,12]$. Our overall findings were in accordance with the known preferences of the species [7, 12]. For example, the immature samples of $C x$. tritaeniorhynchus and $C x$. perexiguus were collected more frequently from flooded land than artificial containers, while specimens of Cx. pusillus and Ae. caspius were frequently found in wetlands with brackish water. However, we were surprised to find Cx. pusillus in a metallic cistern filled with fresh water. The Cs. longiareolata samples, both adults and immatures, were collected from four different sites. This is the first time Cs. longiareolata specimens were detected in Qatar. Wetlands and rural habitats showed the highest mosquito fauna diversity (six species among seven) in comparison to other habitats such as agricultural land, suburban and urban habitats, which harboured at least four species. All these findings are of public health significance in terms of risk for nuisance or potential for pathogen transmission.

\section{Critical review of the species list}

No invasive species were found during our surveys. Despite large scale inspection of many man-made containers located in both urban and suburban habitat, our surveys did not find even a single sample of Aedes (Stegomyia) aegypti (Linnaeus 1762), suggesting that this species is potentially uncommon in Qatar. The occurrence of the yellow fever mosquito, Ae. aegypti, was reported in Qatar in a single reference without providing any sampling details [2]. Nevertheless, the presence of Ae. aegypti in Qatar is hardly surprising, as it is reported to breed in several neighbouring countries. We need to be watchful about its possible import into Qatar by being vigilant at places of entry for goods (port, airport, road crossings). 
Table 4. Mosquito species observed during our sessions 2 and 3 field surveys in Qatar, September 2017 and January 2019, per site. Within rounded parentheses: adults obtained by rearing of immatures; Within braces: number of traps. $\mathrm{F}=$ female; $\mathrm{L}=$ larva; $\mathrm{M}=$ male; $\mathrm{P}=$ pupa.

\begin{tabular}{|c|c|c|c|c|}
\hline Site ID & Date & Method & Numbers and stages observed & Species \\
\hline Q01a & 20.01 .2019 & Larval sampling & $3 \mathrm{~L}(1 \mathrm{~F})$ & Culex tritaeniorhynchus \\
\hline \multirow[t]{3}{*}{ Q01b } & 18.09 .2017 & Larval sampling & $20 \mathrm{~L}$ & Anopheles stephensi \\
\hline & & & $15 \mathrm{~L}$ & Culex quinquefasciatus \\
\hline & & & $25 \mathrm{~L}$ & Culiseta longiareolata \\
\hline Q01b & 20.01.2019 & Larval sampling & $3 \mathrm{~L}$ & Culiseta longiareolata \\
\hline Q01c & 20.01.2019 & Resting catch & $9 \mathrm{M}, 4 \mathrm{~F}$ & Culex quinquefasciatus \\
\hline \multirow[t]{2}{*}{ Q02 } & 20.09.2017 & Larval sampling & $40 \mathrm{~L}, 9 \mathrm{P}(7 \mathrm{M}, 10 \mathrm{~F})$ & Culex pusillus \\
\hline & & & $6 \mathrm{~L}(1 \mathrm{~F})$ & Culex tritaeniorhynchus \\
\hline Q03 & 20.09.2017 & Resting catch + Human landing catch & $1 \mathrm{M}, 2 \mathrm{~F}$ & Aedes caspius \\
\hline Q03 & 17.01.2019 & Human landing catch & $1 \mathrm{~F}$ & Aedes caspius \\
\hline \multirow[t]{2}{*}{ Q04 } & 20.09.2017 & Larval sampling & $56 \mathrm{~L}, 12 \mathrm{P}(23 \mathrm{M}, 19 \mathrm{~F})$ & Culex pusillus \\
\hline & & & $2 \mathrm{~L}, 1 \mathrm{P}(1 \mathrm{M}, 1 \mathrm{~F})$ & Aedes caspius \\
\hline \multirow[t]{5}{*}{ Q04 } & 17.01.2019 & Larval sampling & $1 \mathrm{~L}$ & Aedes caspius \\
\hline & & & $12 \mathrm{~L}, 5 \mathrm{P}(4 \mathrm{M}, 2 \mathrm{~F})$ & Anopheles stephensi \\
\hline & & & $25 \mathrm{~L}, 10 \mathrm{P}(6 \mathrm{M}, 12 \mathrm{~F})$ & Culex perexiguus \\
\hline & & & $50 \mathrm{~L}, 15 \mathrm{P}(20 \mathrm{M}, 18 \mathrm{~F})$ & Culex pusillus \\
\hline & & & $1 \mathrm{~L}, 1 \mathrm{P}(1 \mathrm{~F})$ & Culex quinquefasciatus \\
\hline Q05 & 20.09.2017 & Larval sampling & $6 \mathrm{~L}(1 \mathrm{~F})$ & Culex pusillus \\
\hline \multirow[t]{2}{*}{ Q06 } & 16.01 .2019 & Larval sampling & $1 \mathrm{~L}(1 \mathrm{~F})$ & Culex perexiguus \\
\hline & & & $15 \mathrm{~L}(3 \mathrm{M}, 3 \mathrm{~F})$ & Culex quinquefasciatus \\
\hline Q07 & 16.01.2019 & Larval sampling & $22 \mathrm{~L}, 2 \mathrm{P}(2 \mathrm{M})$ & Culex pusillus \\
\hline \multirow[t]{3}{*}{ Q08 } & 17.01.2019 & Adult trapping $\{3\}$ & $1 \mathrm{~F}$ & Anopheles stephensi \\
\hline & & & $1 \mathrm{M}, 33 \mathrm{~F}$ & Culex quinquefasciatus \\
\hline & & & $9 \mathrm{~F}$ & Culex tritaeniorhynchus \\
\hline \multirow[t]{4}{*}{ Q09 } & 17.01.2019 & Larval sampling & $1 \mathrm{~L}$ & Anopheles stephensi \\
\hline & & & $2 \mathrm{~L}(1 \mathrm{M})$ & Culex perexiguus \\
\hline & & & $48 \mathrm{~L}, 5 \mathrm{P}(2 \mathrm{M}, 5 \mathrm{~F})$ & Culex quinquefasciatus \\
\hline & & & $4 \mathrm{~L}$ & Culex tritaeniorhynchus \\
\hline \multirow[t]{2}{*}{ Q10 } & 17.01.2019 & Larval sampling & $25 \mathrm{~L}(1 \mathrm{~F})$ & Culex perexiguus \\
\hline & & & $5 \mathrm{~L}(1 \mathrm{M}, 2 \mathrm{~F})$ & Culex tritaeniorhynchus \\
\hline \multirow[t]{2}{*}{ Q11 } & 17.01.2019 & Larval sampling & $3 \mathrm{~L}(1 \mathrm{~F})$ & Aedes caspius \\
\hline & & & $12 \mathrm{~L}$ & Culex quinquefasciatus \\
\hline \multirow[t]{2}{*}{ Q12 } & 17.01.2019 & Larval sampling & $100 \mathrm{~L}, 5 \mathrm{P}(3 \mathrm{M}, 2 \mathrm{~F})$ & Culex perexiguus \\
\hline & & & $5 \mathrm{~L}, 1 \mathrm{P}(1 \mathrm{~F})$ & Culex tritaeniorhynchus \\
\hline Q13 & 19.01.2019 & Larval sampling & $180 \mathrm{~L}, 7 \mathrm{P}(6 \mathrm{M}, 1 \mathrm{~F})$ & Culex quinquefasciatus \\
\hline Q14a & 21.01.2019 & Adult trapping $\{3\}$ & $1 \mathrm{M}, 17 \mathrm{~F}$ & Culex quinquefasciatus \\
\hline \multirow[t]{3}{*}{ Q14b } & 21.01.2019 & Larval sampling & $15 \mathrm{~L}, 2 \mathrm{P}(2 \mathrm{~F})$ & Anopheles stephensi \\
\hline & & & $32 \mathrm{~L}, 2 \mathrm{P}(1 \mathrm{M}, 1 \mathrm{~F})$ & Culex quinquefasciatus \\
\hline & & & $25 \mathrm{~L}$ & Culiseta longiareolata \\
\hline \multirow[t]{2}{*}{ Q15 } & 21.01.2019 & Larval sampling & $4 \mathrm{~L}$ & Culex perexiguus \\
\hline & & & $35 \mathrm{~L}$ & Culex quinquefasciatus \\
\hline \multirow[t]{3}{*}{ Q16 } & 21.01.2019 & Larval sampling & $1 \mathrm{~L}$ & Anopheles stephensi \\
\hline & & & $1 \mathrm{~L}$ & Culex perexiguus \\
\hline & & & $18 \mathrm{~L}, 4 \mathrm{P}(3 \mathrm{M}, 1 \mathrm{~F})$ & Culex quinquefasciatus \\
\hline Q17a & 21.01.2019 & Larval sampling & $4 \mathrm{~L}$ & Culex quinquefasciatus \\
\hline Q17b & 21.01.2019 & Resting catch & $4 \mathrm{M}, 6 \mathrm{~F}$ & Culex quinquefasciatus \\
\hline Q17c & 22.01.2019 & Adult trapping $\{1\}$ & - & - \\
\hline Q18 & 21.01.2019 & Larval sampling & $50 \mathrm{~L}, 14 \mathrm{P}(8 \mathrm{M}, 6 \mathrm{~F})$ & Culex quinquefasciatus \\
\hline \multirow[t]{2}{*}{ Q19 } & 22.01.2019 & Adult trapping $\{1\}$ & $1 \mathrm{M}$ & Aedes caspius \\
\hline & & & $2 \mathrm{M}, 29 \mathrm{~F}$ & Culex quinquefasciatus \\
\hline Q20 & 21.01.2019 & Larval sampling & $60 \mathrm{~L}, 2 \mathrm{P}(2 \mathrm{~F})$ & Culex perexiguus \\
\hline
\end{tabular}

Similarly, an investigation for the possible introduction and presence of another invasive species, the Asian tiger mosquito Ae. (Stg.) albopictus (Skuse, 1894), which also inhabits artificial collection of water (e.g. containers) should be performed. Additionally, authorities need to be especially vigilant since this species is spreading worldwide and is even found in the Middle East (e.g. in Iran, Gulf of Oman coast; [9]). Intense international trade makes its introduction possible, and the local climate looks suitable for its establishment [10].

Two brackish-water wetland mosquitoes are reported to occur in Qatar. The first, Ae. caspius, looks to be widespread in the country based on our findings (Table 5). Previous studies have also reported the presence of these species in Qatar for long time. It is possible that the population of this particular 


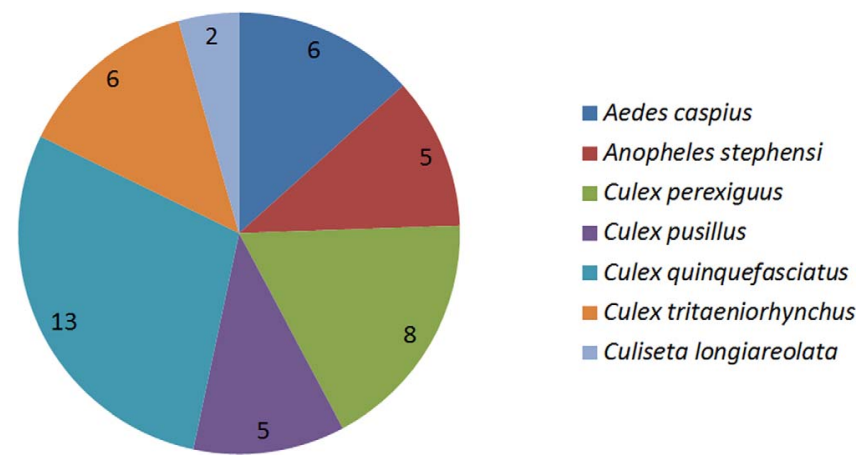

Figure 3. Numbers of positive sites for every mosquito species observed during our field surveys in Qatar, September 2017 and January 2019, by any sampling method, for a total number of 20 sites.

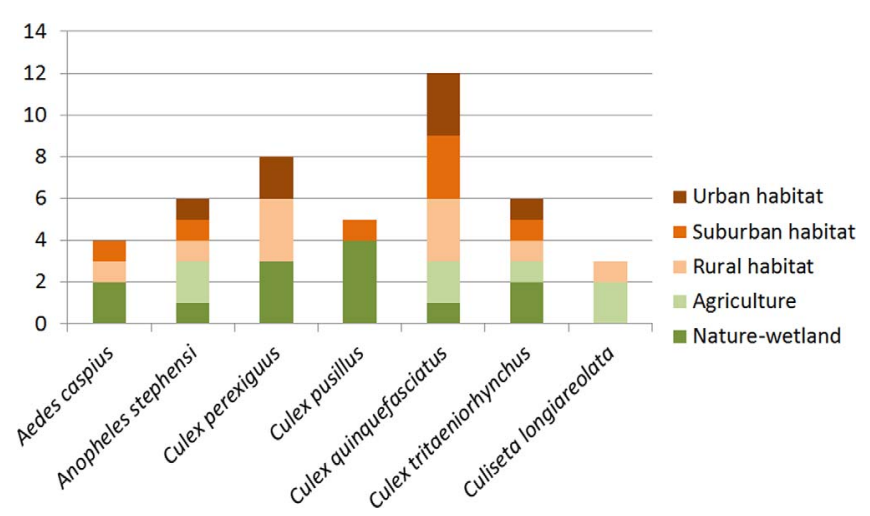

Figure 4. Numbers of positive sites for every land use category per mosquito species observed during our field surveys in Qatar, September 2017 and January 2019, by any sampling method, for a total number of 20 sites.

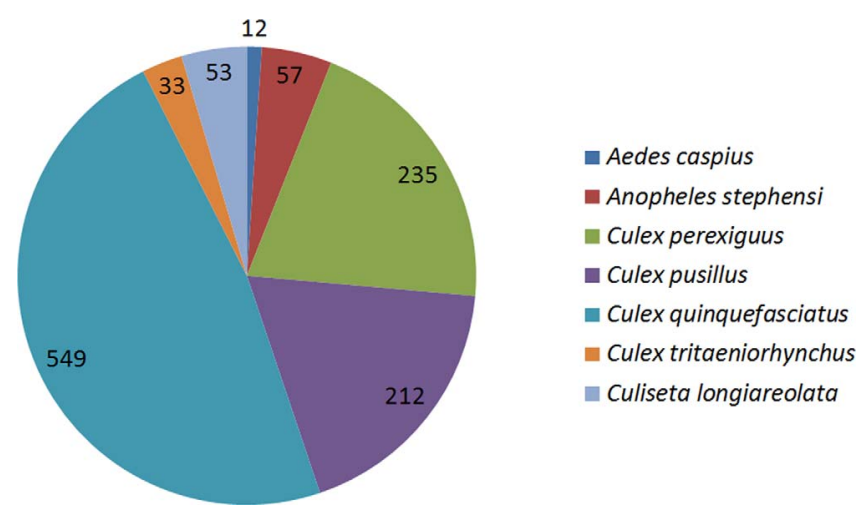

Figure 5. Relative proportions of mosquito species individuals collected during our field surveys in Qatar, September 2017 and January 2019 , by any sampling method, for a total number of 1,151 individuals.

species may increase following rainfall or artificial accumulation of water in sewage lakes, and subsequently disperse over several kilometres and bite the human population, causing nuisance. A second species, Ae. (Och.) dorsalis (Meigen, 1830), which has been reported only once before [15], shares many morphological characters with Ae. caspius. This particular species if known to have a northern Holarctic distribution; however, it has never been reported from any other country in the Middle East except Iraq and Turkey [2, 22]. In addition, Ae. caspius adults show morphological variabilities, which could cause its misidentification as Ae. dorsalis [7]. Therefore, the present study recommends that the presence of Ae. dorsalis should be further studied in Qatar with sample collections, morphological observations and molecular identification.

Four Anopheles species are reported to inhabit Qatar (Table 5). The most frequently reported species, An. stephensi, was also observed in our study. While the presence of $A n$. (Cel.) multicolor Cambouliu, 1902 is suggested by two field studies [15, 18], the two other species An. (Cel.) culicifacies s.l. Giles, 1901 and An. (Cel.) sergentii (Theobald, 1907) are listed without any field observation data $[2,11]$ and therefore their presence has to be substantiated.

The mosquito species belonging to the genus Culex are the most widespread mosquitoes in Qatar. In the Middle East, the Culex pipiens complex comprises the two forms pipiens and molestus, and $C x$. quinquefasciatus $[13,22]$. However, distinguishing these species by morphology is a difficult task that requires meticulous specimen examination [7]. In our study, all specimens were identified as $C x$. quinquefasciatus, including by molecular examination. Several articles on the Qatari fauna refer to the $C x$. pipiens complex $[1,18,19]$, while others mention both Cxpipiens form molestus and Cx. quinquefasciatus to occur $[14,15]$. Therefore, further sampling and molecular examination is recommended to confirm the identity of the Culex pipiens complex members in Qatar.

Culex (Cux.) univittatus Theobald, 1901 and Cx. perexiguus are two other closely related species that exhibit very similar external morphology at all life stages [7]. Both species have been reported in the Arabian Peninsula [12] as well as in Qatar $[14,18]$. In our study, we identified only $C x$. perexiguus, confirmed by molecular identification. As for the pipiens complex, there is unclear morphological differentiation and thus further molecular examination is recommended for specimens attributed by morphology to $C x$. univittatus [20]. The presence of Cx. pusillus and Cx. tritaeniorhynchus in Qatar was confirmed by our field studies, whereas five other Culex species reported in the literature were not found viz. Cx. (Oculeomyia) bitaeniorhynchus Giles, 1901, Cx. (Cux.) laticinctus Edwards, 1913, Cx. (Cux.) mimeticus Noè, 1899, Cx. (Cux.) sitiens Wiedemann, 1828, and Cx. (Cux.) vagans Wiedemann, 1828. All of them except $C x$. vagans do occur in the Arabian Peninsula [2, 12, 22], but to date, there has been only a single record in the literature and thus the occurrence of these five species in Qatar remains to be confirmed.

Lastly, there is only one official record of detection of Culiseta sp. (under its synonym Theobaldia) [1] and for Coquillettidia sp. in Qatar [21]. The mention of Culiseta may refer to Cs. longiareolata that we report here for the first time, and the presence of Coquillettidia sp. has to be further investigated.

\section{Recommendations to further explore local mosquito fauna}

Additional and extended field surveys should be performed at regular interval to provide the most comprehensive 
Table 5. Mosquito taxa reported to occur in Qatar in the literature, with date of first report, our findings, and assessed occurrence status. Black dots $=$ confirmed presence.

\begin{tabular}{|c|c|c|c|c|c|c|}
\hline Taxon & $\begin{array}{l}\text { First } \\
\text { report }\end{array}$ & $\begin{array}{l}\text { References } \\
\text { for Qatar }\end{array}$ & $\begin{array}{c}\text { Session } 1 \\
2017- \\
2018\end{array}$ & $\begin{array}{c}\text { Session } 2 \\
2017\end{array}$ & $\begin{array}{c}\text { Session } 3 \\
2019\end{array}$ & Occurrence status \\
\hline$\overline{\text { Aedes aegypti }}$ & 1999 & [2] & & & & Introduced? \\
\hline Aedes caspius & 2009 & {$[14,15,18]$} & O & 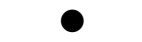 & 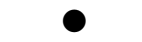 & Native \\
\hline Aedes dorsalis & 2015 & [15] & & & & ${ }^{1}$ Presence to be confirmed \\
\hline Anopheles culicifacies s.l. & 1999 & [2] & & & & ${ }^{1}$ Presence to be confirmed \\
\hline Anopheles multicolor & 1992 & {$[11,15,18]$} & & & & Native \\
\hline Anopheles sergentii & 1992 & [11] & & & & ${ }^{1}$ Presence to be confirmed \\
\hline Anopheles stephensi & 1999 & {$[2,14,15,18,21]$} & ○ & & - & Native \\
\hline Culex bitaeniorhynchus & 2015 & [21] & & & & ${ }^{1}$ Presence to be confirmed \\
\hline Culex laticinctus & 2015 & {$[14]$} & & & & ${ }^{1}$ Presence to be confirmed \\
\hline Culex mimeticus & 2015 & {$[21]$} & & & & ${ }^{1}$ Presence to be confirmed \\
\hline Culex pipiens ${ }^{2}$ complex & 1985 & {$[1,14,15,18,19]$} & & & & $\begin{array}{l}\text { Native; Identity of occurring complex } \\
\text { members to be confirmed }\end{array}$ \\
\hline Culex perexiguus & 2015 & [14] & & & 0 & Native \\
\hline Culex pusillus & 2009 & {$[14,18]$} & ? & 0 & 0 & Native \\
\hline Culex quinquefasciatus & 1988 & {$[2,12,14,15,19]$} & $\mathbf{0}^{3}$ & & 0 & Native; Member of pipiens complex \\
\hline Culex sitiens & 2015 & [14] & & & & ${ }^{1}$ Presence to be confirmed \\
\hline Culex tritaeniorhynchus & 2015 & {$[14,15]$} & - & ○ & ○ & Native \\
\hline Culex univittatus & 2009 & {$[14,18]$} & & & & $\begin{array}{l}\text { Native; Identity to be confirmed by } \\
\text { sequencing }\end{array}$ \\
\hline Culex vagans & 2015 & {$[21]$} & & & & ${ }^{1}$ Presence to be confirmed \\
\hline Culiseta $\mathrm{sp}$. & 1985 & {$[1]$} & & & & ${ }^{1}$ May refer to Cs. longiareolata \\
\hline Culiseta longiareolata & This study & - & ? & & 0 & Native \\
\hline Coquillettidia $\mathrm{sp}$. & 2015 & {$[21]$} & & & & ${ }^{1}$ Presence to be confirmed \\
\hline Total numbers: & 21 & & 6 & 3 & 7 & \\
\hline
\end{tabular}

${ }^{1}$ Single record;

${ }^{2}$ Mentioned as pipiens complex or form molestus;

${ }^{3}$ As a group of three possible species, $C x$. perexiguus, $C x$. pipiens and $C x$. quinquefasciatus.

knowledge about the mosquito fauna in Qatar. The most comprehensive strategy would be to undertake a field survey at as many sites as possible throughout the country, covering all kinds of environments and applying various sampling and trapping methods, more intensely during the rainy season but also the rest of year.

While city parks may not provide relevant mosquito fauna data because of their regular treatment by insecticides, wildlife conservation centres and animal holdings are important to investigate. In addition, surveys should focus on points of entry (ports, airports) as well as labour camps and industrial zones for possible alien species introductions. There are chances of discovering previously undetected mosquito species in Qatar given the existence of many other species in neighbouring countries (e.g. 36 species in Saudi Arabia [2]). However, the most pressing priority must be to design field surveys to confirm the existence of the mosquito species reported to occur in Qatar only by a single study/sample (Table 5). A quick way of achieving this could be re-analysis of the already collected specimens preferentially by a third party (providing the samples are preserved by the institutes after completion of field surveys) [13, 14, 19]. Another way of achieving this would be to sample at the same locations as mentioned by authors in those studies, possibly at the same time of the year.

Besides mapping the mosquito population in Qatar, entomological surveys should also aim to evaluate the risk of mosquito-borne pathogen transmission by collecting data on distribution, abundance, seasonality and biting behaviour of species. Such surveys may focus on (1) Anopheles species as potential vectors of malaria parasites, (2) Ae. aegypti and Ae. albopictus as potential vectors of chikungunya, dengue, and Zika viruses, (3) Ae. caspius as a potential vector of Rift Valley fever virus, and (4) Cx. pipiens complex, $C x$. perexiguus, $C x$. tritaeniorhynchus, and $C x$. univittatus as potential vectors of West Nile virus. Finally, cross-sectional and longitudinal data collections are needed to support the building of mid- and long-term surveillance and control strategies.

\section{Summary outcome and prospects}

Our field studies have immensely extended the length, breadth, and depth of Qatar's existing mosquito fauna database. Our field surveys were neither able to confirm nor refute the existence of Ae. aegypti in Qatar; however, given the extensive geographical coverage and length of sample collection, we can confidently say that Ae. aegypti is neither widespread nor abundant in Qatar. This suggests that there is a minimal risk for local transmission of dengue, chikungunya or Zika viruses. The malaria vector An. stephensi is widespread and common, including in urbanised areas, suggesting a risk of local transmission of malaria parasites. The wetland mosquito Ae. caspius is likewise widespread and is probably responsible for biting 
nuisance at certain periods of the year, also representing a risk of Rift Valley fever virus transmission. Several potential vectors of West Nile virus are present in Qatar. The species $C x$. quinquefasciatus, commonly known as the southern house mosquito, was present most abundantly and this species is mostly responsible for the indoor biting nuisance. Regular field studies are needed to further address the knowledge gaps in terms of distribution, breeding and biting preferences of different mosquito species currently present in Qatar to accurately assess the risk of mosquito-borne diseases [8, 27].

\section{Conflict of interest}

The authors declare that they have no competing interests.

Acknowledgements. We are pleased to thank WHO Eastern Mediterranean Regional Office and in particular Dr Gashem Zamani for funding the start of this study, i.e. the vector control situation analysis and needs assessment performed in 2017. We also express our gratitude and appreciation to $\mathrm{MoPH}$, for support with staff and funding of the field studies. We also thank the Friends of Environment Center for their support in sample collection, as well as colleagues of Doha and Al Rayyan pest control units for assisting in the field work. DB and EABAF benefit from a NPRP grant [NPRP12S-0310-190284] from the Qatar National Research Fund (a member of Qatar Foundation). The Swiss Federal Food Safety and Veterinary Office is highly acknowledged as sponsor of the National Centre for Vector Entomology, and Jeannine Hauri (Institute of Parasitology, University of Zurich, Switzerland) for genetic analyses. We finally thank Alexander Weigand (National Museum of Natural History Luxembourg) and Yuki Haba (Princeton University, USA) for complementary genetic analysis.

\section{References}

1. Abdu RM, Shaumar NF. 1985. A preliminary list of the insect fauna of Qatar. Qatar University Science Bulletin, 5, $215-232$

2. AFPMB. 1999. Regional disease vector ecology profile. The Middle East. p. 1-209. https://permanent.access.gpo.gov/ lps28798/mid_east.pdf.

3. Al Ahmad AM, Sallam MF, Khuriji MA, Kheir SM, AzariHamidian S. 2011. Checklist and pictorial key to fourth-instar larvae of mosquitoes (Diptera: Culicidae) of Saudi Arabia. Journal of Medical Entomology, 48(4), 717-737.

4. Alahmed AM, Munawar K, Khalil SMS, Harbach RE. 2019. Assessment and an updated list of the mosquitoes of Saudi Arabia. Parasites \& Vectors, 12(1), 356.

5. Anonymous. 2017. Qatar. IndexMundi. http://www.indexmundi. com/facts/qatar/. Accessed 15 April 2021.

6. Anonymous. 2020. Qatar climate. https://en.climate-data.org/ asia/qatar-183/. Accessed 15 April 2021.

7. Becker N, Petric D, Zgomba M, Boase C, Madon M, Kaiser A. 2010. Mosquitoes and their control, 2nd edn. Springer-Verlag: Berlin, Heidelberg.

8. Braks M, van der Giessen J, Kretzschmar M, van Pelt W, Scholte E-J, Reusken C, Zeller H, van Bortel W, Sprong H. 2011. Towards an integrated approach in surveillance of vectorborne diseases in Europe. Parasites \& Vectors, 4(1), 192.

9. Doosti S, Yaghoobi-Ershadi MR, Schaffner F, Moosa-Kazemi SH, Akbarzadeh K, Gooya MM, Vatandoost H, Shirzadi MR,
Mosta-Favi E. 2016. Mosquito surveillance and the first record of the invasive mosquito species Aedes (Stegomyia) albopictus (Skuse) (Diptera: Culicidae) in Southern Iran. Iranian Journal of Public Health, 45(8), 1064-1073.

10. Ducheyne E, Tran Minh NN, Haddad N, Bryssinckx W, Buliva E, Simard F, Malik MR, Charlier J, De Waele V, Mahmoud O, Mukhtar M, Bouattour A, Hussain A, Hendrickx G, Roiz D. 2018. Current and future distribution of Aedes aegypti and Aedes albopictus (Diptera: Culicidae) in WHO Eastern Mediterranean Region. International Journal of Health Geographics, 17(1), 4.

11. Glick JI. 1992. Illustrated key to the female Anopheles of Southwestern Asia and Egypt (Diptera: Culicidae). Mosquito Systematics, 24(2), 125-153.

12. Harbach RE. 1988. The mosquitoes of the subgenus Culex in southwestern Asia and Egypt (Diptera: Culicidae). Contributions of the American Entomological Institute, 24(1), 1-240.

13. Harbach RE. 2012. Culex pipiens: Species versus species complex - Taxonomic history and perspective. Journal of the American Mosquito Control Association, 28(4s), 10-23.

14. Kardousha MM. 2015. Additional records of vector mosquito diversity collected from Al Khor district of North-eastern Qatar. Asian Pacific Journal of Tropical Disease, 5(10), 804-807.

15. Kardousha MM. 2016. First report of some adult mosquitoes captured by CDC gravid traps from North-Eastern Qatar. Asian Pacific Journal of Tropical Disease, 6(2), 100-105.

16. Linton Y-M, Harbach RE, Seng CM, Anthony TG, Matusop A. 2001. Morphological and molecular identity of Anopheles (Cellia) sundaicus (Diptera: Culicidae), the nominotypical member of a malaria vector species complex in Southeast Asia. Systematic Entomology, 26(3), 357-366.

17. Mathieu K, Karmali M. 2016. Vector-borne diseases, climate change and healthy urban living: Next steps. Canada Communicable Disease Report, 42(10), 219-221.

18. Mikhail MW, Al-Bursheed KM, Abd El-Halim AS, Morsy TA. 2009. Studies on mosquito borne dieases in Egypt and Qatar. Journal of the Egyptian Society of Parasitology, 39(3), 745-756.

19. Mikhail MW, Al-Bursheed KM, Allam KAM. 2007. Susceptibility of Culex pipiens complex to some insecticides in Qatar. Journal of the Egyptian Society of Parasitology, 37(3), 893-902.

20. Mixão V, Bravo Barriga D, Parreira R, Novo MT, Sousa CA, Frontera E, Venter M, Braack L, Almeida APG. 2016. Comparative morphological and molecular analysis confirms the presence of the West Nile virus mosquito vector, Culex univittatus, in the Iberian Peninsula. Parasites \& Vectors, 9(1), 601.

21. Rabab IA. 2015. The most common mosquitoes at Al-Rayyan municipality (Qatar state) and their potential for transmitting malaria. Ms Thesis. Qatar University: Doha.

22. Robert V, Günay F, Le Goff G, Boussès $P$, Sulesco T, Khalin A, Medlock JM, Kampen H, Petrić D, Schaffner F. 2019. Distribution chart for Euro-Mediterranean mosquitoes (western Palaearctic region). Journal of the European Mosquito Control Association, 37, 1-28.

23. Schaffner F, Angel G, Geoffroy B, Hervy J-P, Rhaiem A, Brunhes J. 2001. The Mosquitoes of Europe / Les moustiques d'Europe. IRD Editions \& EID Méditerranée: Montpellier. CDROM

24. Schaffner F, Bansal D, Al-Thani MHJ, Al-Romaihi H, Farag EABA. 2021. Preventing vector-borne diseases at major sport events: Addressing the challenges for FIFA 22 in Qatar. PLOS Neglected Tropical Diseases, 15(3), e0009135.

25. Schaffner F, Bansal D, Mardini K, Al-Marri SA, Al-Thani MHJ, Al-Romaihi H, Sultan AA, Al-Hajri M, Farag EABA. 2021. Vectors and vector-borne diseases in Qatar: current status, key challenges and future prospects. Journal of the European Mosquito Control Association, 39(1), 3-13. 
26. Schönenberger AC, Wagner S, Tuten HC, Schaffner F, Torgerson P, Furrer S, Mathis A, Silaghi C. 2016. Host preferences in host-seeking and blood-fed mosquitoes in Switzerland. Medical and Veterinary Entomology, 30(1), 39-52.

27. Sedda L, Morley DW, Braks MAH, De Simone L, Benz D, Rogers DJ. 2014. Risk assessment of vector-borne diseases for public health governance. Public Health, 128(12), 1049-1058.
28. Smith JL, Fonseca DM. 2004. Rapid assays for identification of members of the Culex (Culex) pipiens complex, their hybrids, and other sibling species (Diptera: culicidae). American Journal of Tropical Medicine and Hygiene, 70(4), 339-345.

29. Valenzuela JG, Aksoy S. 2018. Impact of vector biology research on old and emerging neglected tropical diseases. PLOS Neglected Tropical Diseases, 12(5), e0006365.

Cite this article as: Farag EABA, Bansal D, Mardini K, Sultan AA, Al-Thani MHJ, Al-Marri SA, Al-Hajri M, Al-Romaihi H \& Schaffner F. 2021. Identification and characterisation of mosquitoes from different locations of Qatar in 2017-2019. Parasite 28 , 84.

\section{- PARASTE}

An international open-access, peer-reviewed, online journal publishing high quality papers on all aspects of human and animal parasitology

Reviews, articles and short notes may be submitted. Fields include, but are not limited to: general, medical and veterinary parasitology; morphology, including ultrastructure; parasite systematics, including entomology, acarology, helminthology and protistology, and molecular analyses; molecular biology and biochemistry; immunology of parasitic diseases; host-parasite relationships; ecology and life history of parasites; epidemiology; therapeutics; new diagnostic tools.

All papers in Parasite are published in English. Manuscripts should have a broad interest and must not have been published or submitted elsewhere. No limit is imposed on the length of manuscripts.

Parasite (open-access) continues Parasite (print and online editions, 1994-2012) and Annales de Parasitologie Humaine et Comparée (1923-1993) and is the official journal of the Société Française de Parasitologie. 